\title{
NOTE FROM THE EDITORS
}

For some time now, members of our editorial board and interested readers have urged us to undertake the selective publication of interesting articles from Soviet and Bloc journals.

We begin such a process with Merab Mamardašvili's 'Analysis of Consciousness in the Works of Marx' because it represents one of the most original analyses of the thought of Marx done in the Soviet Union during the past two decades.

The editors hope that the readers will find this article worth the reprinting and will let us have their comments and critiques.

Suggestions for further items in the translation effort will be most welcome. 